\title{
PARENTAL PERCEPTIONS AND PRACTICES OF EMERGENT LITERACY DEVELOPMENT IN YOUNG CHILDREN WITH DOWN SYNDROME: THE DEVELOPMENT OF INTERVENTION GUIDELINES
}

\author{
Cherié van Heerden and Alta Kritzinger \\ Clinic for High Risk Babies (CHRIB) Centre, University of Pretoria, South Africa
}

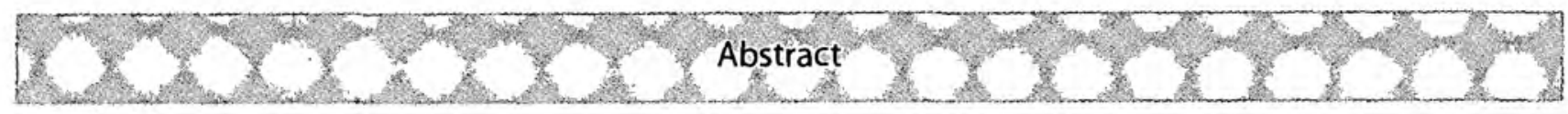

Key findings of emergent literacy research conclude that emergent literacy experiences correlate with later reading success and thatemergent literacyinterventionforchildren with specialneedsisessential.Asagroup with special needs, children with Down syndrome require emergent literacy intervention. They may attain functional literacyskills and theirlanguage development determines their reading ability.Speech-language therapists have an important role to play in emergent literacy programme development in South Africa. As a first step towards programme development and emergent literacy intervention goal selection, the aim of this study was to determine the applicability of a self-administered questionnaire to describe parental perceptions and practices regarding the emergent literacy development of theiryoung children with Down syndrome.Aquantitativeresearchapproach wasused withinacross-sectionaldescriptivesurvey. Fifteen literate parents, with preschool children with Down syndrome aged between two and five years were selected as participants. Data werecollected viaemailand/orfacsimile. Theresultsshowed that allparticipantsvalued emergent literacy development. They appeared to have knowledge about book-reading but not about the broad spectrum of emergent literacy experiences to which they might expose their children. Participants were actively promoting emergent literacy development of their children, but they had certain needs that could potentiallybeaddressedbyspeech-languagetherapistsworking inearlycommunication intervention. The questionnaire proved to be applicable, but changes are required for application with illiterate parents and thosewith lowliteracy skills. Based on the results a framework with guidelines for emergent literacy goal selection is provided.

Key words: Emergent literacy development; parental perceptions; emergent literacy intervention; Down syndrome; early communication intervention.

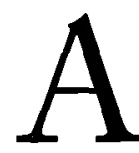

s a developmental construct emergent literacy has become a dynamic field of study in recent years. Key research findings such as the correlation between emergent literacy experiences and later reading success, and the necessity of emergent literacy intervention for children with special needs (Ezell \& Justice, 2005), focus the attention on the importance of emergent literacy knowledge and facilitation skills for all involved in early childhood interventions.

In the USA,ASHA (2001) advocates the view that speech-language therapists play an important role in promoting literacy for young children with communication disorders. However, there appears to be a dearth of information on the promotion of emergent literacy development across the diverse spectrum of South African contexts, despite the fact that many young children are at risk for communication disorders and have special needs. Apart from a major study by Willenberg (2007) on the emergent literacy competencies of Grade $R$ learners on the Cape Flats in the Western Cape Province and the development of an assessment tool for young children, the inclusion of literacy skills in early communication assessment protocols (Kritzinger \& Steenkamp, 2006; Kritzinger \& Louw, 2002), and minor surveys such as Kritzinger and Louw (1997), Pieterse (1998) and Prinsloo (1998) to determine awareness of emergent

Author Contact: Cherié van Heerden and Alta Kritzinger, Clinic for High Risk Babies (CHRIB) Centre,

University of Pretoria,

Lynwood Road,

Pretoria, 0001

South Africa 
literacy skills among parents, little is known about intervention efforts by speech-language therapists in South Africa during the earliest stage of literacy development.

In a literate context, emergent literacy represents the first stage (birth to five years), followed by the early literacy stage (five to seven years) on the continuum of literacy development (Justice, 2006). According to Ezell and Justice (2005), emergent literacy describes the concepts, skills and knowledge that preschool children acquire about the process of reading and writing before beginning their formal education. Emergent literacy not only refers to the child's foundational skills of print knowledge, but also includes phonological awareness, writing skills such as invented writing and name writing, and oral language skills, which include grammar, vocabulary and narration. Although emergent literacy development is closely related to language and communication development (Owens, 2005), it constitutes a separate developmental construct and is not merely a useful medium to facilitate early language development.

Typical characteristics of children in the emergent literacy stage of development include having a keen interest in print despite not being able to read, viewing themselves as being able to read, particularly with familiar storybooks, playing with writing utensils and media, viewing their reading and writing attempts as meaningful, using and enjoying books as a play or relationship-building activity, playing with the phonology of oral language, such as reciting or making up rhymes, identifying alliterative patterns across words, demonstrating awareness of words, syllables, phonemes and numbers, and utilising literacy themes or props within their dramatic play. Exposure to print includes being made aware of print in books and in the everyday environment such as street signs and brand names on products, the ability to handle books correctly, the knowledge of print directionality and the knowledge of major book elements, such as knowing that the cover of a book holds the title of the book, as well as exposure to numeracy skills (Boudreau, 2002; Buckley, 2000; Justice, 2006).

Since acquisition of these diverse emergent literacy characteristics and skills facilitates successful reading at a later stage (Ezell \&Justice, 2005), emergent literacy development should begin very early in a child's life. Exposure to a rich variety of books at home, in early childcare settings and preschools is assumed. Emergent literacy centers around books and may be viewed as a non-essential commodity when resources are scarce. These important developmental experiences may not be accessible to all children in South Africa, including those with special needs. Local research is therefore needed to determine the nature of emergent literacy development in young children from families who represent the entire spectrum of literacy, from fully literate, to those with low literacy skills, to illiteracy. Data obtained can direct emergent literacy intervention programmes to train parents and caregivers to optimise the emergent literacy stage of young children with various special needs. The involvement of parents and caregivers in emergent literacy development is consistent with the emergent literacy intervention approach (Justice, 2006) and the principles of early communication intervention (Rossetti, 2001).

According to Kumin (2003) reading can be a very suc- cessful route in assisting children with Down syndrome to learn language, and emergent literacy experiences have positive effects on receptive and expressive language, cognitive and memory skills. Emergent literacy skills were found to enhance a young child's vocabulary, speech and other expressive language skills such as syntax, morphological skills and syntax length, the initiation of conversation, understanding of concepts and awareness of sound structure. The future learning of young children with Down syndrome is also enhanced as emergent literacy promotes reading and writing, educational progress, inclusion, independence, opportunities for employment and quality of life (Boudreau, 2002; Buckley, 2000; Elias, Hay, Homel, \& Freilberg, 2006; Ezell \& Justice, 2005; Kumin, 2003). Since many children with Down syndrome can attain functional literacy skills in inclusive education (Bochner, Outhred \& Pieterse, 2001) and the finding that language skills are a strong predictor of their reading ability (Boudreau, 2002) it is important that parents and caregivers are sufficiently informed about the long-term effects of early communication and emergent literacy intervention.

Information on the advantages of emergent literacy skills and parental involvement are available to South African parents with children with Down syndrome and who have access to the Internet, on the Down Syndrome Association of South Africa website (www.downsyndrome.org.za/main. aspx?artid=67). The association is also involved in promoting literacy in a paper-based publication, the Down Syndrome Bulletin (2000, 2001, 2002, 2003 and 2006). The question remains as to whether parents actively promote the emergent literacy skills of their children with Down syndrome or if they only have the knowledge of emergent literacy development but do not put this knowledge into practice.

The advantages of emergent literacy intervention are enhanced when children have access to literacy experiences in their homes (Ezell \& Justice, 2006). According to Owens (2006) of all the factors predicting reading success, early book-reading practices by parents to their children and a literate atmosphere at home appear to be most important for early reading success. Elias et al. (2006) confirm that the frequency and quality of parent-child reading is an important determinant of a child's later literacy attainment. Kaderavek and Justice (2004) emphasize that parents can be literacy facilitators, which implies that literacy can be $\mathrm{fa}^{-}$! cilitated throughout the day in a number of different activities. According to Roberts, Jurgens and Burchinal (2005) the responsiveness and support of the home environment is the strongest and most consistent predictor of children's language and emergent literacy skills. These research findings confirm the importance of parent involvement in supporting emergent literacy development. Yet, it appears that they may not always sufficiently facilitate emergent literacy development in their children.

According Ezell and Justice (2005) there is considerable variation among American school children in language and literacy skills when they enter the early literacy stage. The variation may be partly due to insufficient exposure to language-rich experiences during adult-child storybook reading. A local study by Kritzinger and Louw (1997), described the book-reading practices of 25 mothers and their young 
children, 0-2 years old with risks for communication disorders. The results indicated that only $36 \%$ of the mothers were aware of the value of joint book-reading, $12 \%$ were unsure and $52 \%$ were unaware of the value of joint bookreading. In contrast with the majority of participants' lack of knowledge about the benefits of book-reading, a study by Prinsloo (1998) showed that $80 \%$ of the parents with infants aged 6-24 months with Down syndrome knew that their children could benefit from early joint book-reading. These two studies focused on joint book-reading activities only and not on the broader perspective of emergent literacy experiences. Furthermore, these studies were already conducted nine and ten years ago. It is therefore important to continue investigating emergent literacy development in children with Down syndrome so that guidelines for emergent literacy programme development may be obtained.

As research participants, parents and caregivers may be utilised to determine strengths and areas of need in their children's emergent literacy experiences (Bennett, Weigel \& Martin, 2002). Since children with Down syndrome represent a group with special needs that requires emergent literacy and early communication intervention to optimize success in inclusive education (Kumin, 2003), their parents were targeted in the present study. It was not known to what extent parents expose their children to the wide range of activities associated with emergent literacy skills and the value they placed on the development of these skills in their children with Down syndrome. Moreover, it appears there is a dearth of research on emergent literacy development in children with Down syndrome within the South African context. The available literature mostly describes the American and British contexts, including the work of authors such as Bird and Buckley (2007), Boudreau (2002) and Kumin (2003).

In order to start the process of emergent literacy programme development, and to involve parents from the beginning, a self-administered questionnaire was developed to determine parental perceptions of the broad spectrum of emergent literacy activities and what they report doing regarding emergent literacy development in their children. The research question was how applicable the questionnaire proved to be as a tool to determine a literate sample of parents' perceptions and practices of emergent literacy support of their children, and if clinical guidelines might be gained from the results.

\section{Method}

Aims of the study

The main aim of the study was to determine the applicability of a self-administered questionnaire to describe parental perceptions regarding emergent literacy development in their young children with Down syndrome in order to provide guidelines for clinical practice in an emergent literacy intervention programme. The following sub-aims were identified to achieve the main aim:

- To determine the value parents attach to the development of emergent literacy development in their young children with Down syndrome.

To describe the materials parents report using to facilitate the development of emergent literacy in their children.
- To describe parental reporting on how they facilitate the emergent literacy development of their children.

- To determine the parental perceptions of the time they spend on facilitating the emergent literacy development of their children.

To determine the needs of parents to facilitate emergent literacy development in their children.

Research design

The research study took the form of a cross-sectional survey. Data on parental perceptions regarding emergent literacy development of young children with Down syndrome were collected once-off and described without determining relationships between the variables.

A self-administered questionnaire with mostly closedended questions was used to collect data. Data were therefore measurable and could be described quantitatively. Since quantitative research uses methods that enhance objectivity when variables are measured, conclusions may be less biased (Leedy \& Ormrod, 2005). A self-administered questionnaire allowed participants to complete the questions at their own time, without interference from the researcher. Self-administered questionnaires were successfully used in previous studies with parents of children with Down syndrome such as Bennett et al. (2002) and Boudreau (2005). This data collection method also permits anonymity, although it may be compromised when the questionnaire is returned via email or facsimile. The use of electronic media for data collection, however, did not limit the participants to a small geographical area and avoided possible delays with postal services.

\section{Research Ethics}

Ethical clearance was obtained from the Research Ethics Committee of the Department of Communication Pathology, University of Pretoria, before commencing with data collection. Informed consent was obtained from all the research participants. The participants were informed that they could withdraw from the study at any point in the research process.

Data were analysed and reported anonymously, although the one researcher knew the participants' identities, as she received the questionnaires. When questionnaires were returned, all identifying information such as facsimile numbers and email addresses were removed from the copies and coded. At the time of data analysis the questionnaires could not be traced back to any specific participant. No deception was used and data were analyzed and reported from a group perspective. All data were treated with confidentiality and were securely stored according to University regulations.

Participants

Since the study targeted literate parents of young children with Down syndrome (two to five years) to determine the applicability of the questionnaire for this group, a limited number of participants were available. The research participants were selected according to the following criteria:

\section{Parental status}

The research participants were the parents (mothers and or fathers) of young children with Down syndrome, between the ages of two to five years. According to Kumin (2003) and Buckley (2000) young children with Down syndrome of two to three years are usually able to learn to read.

- Language proficiency and level of education 


\section{CHERIE VAN HEERDEN AND ALTA KRITZINGER}

The participants had to be literate and competent in English and/ or Afrikaans in order to answer the questionnaire. This questionnaire was only available in English and Afrikaans. As a first step in emergent literacy programme development, literate parents were targeted in this study. It was hoped that useful information might be gained from this study so that research tools might be designed for followup studies with parents with low literacy and those with limited functional literacy skills.

Access to technology

The participants needed to have had access to either Internet or facsimile facilities in order to be able to receive and return the questionnaires. Access to the Internet and facsimile were required, as these options are more efficient than postal services and suited the short duration of the research project.

- Geographical location

Since the study was conducted via email and/or facsimile, the participants were not limited to a specific geographical region.

For the purpose of this study, inclusion criteria did not require that the toddlers with Down syndrome had received speech therapy in the past or were receiving therapy at the time of the study.

\section{Participant sampling design}

Two sampling procedures were selected for this study, namely purposeful sampling and snowball sampling. According to Struwig and Stead (2001), purposeful sampling provides a sample of information-rich participants as the participants show specific characteristics that the researcher is interested in. The Down Syndrome Association of South Africa was contacted and a list with potential participants for the study was obtained. Participants were also selected from the Clinic for High Risk Babies (CHRIB) research database, University of Pretoria. The CHRIB database contains datasets of families who have children with developmental disabilities, including Down syndrome (Kritzinger, Louw \& Rossetti, 2001). Families with children with Down syndrome aged between two and five years old were recruited.

Additional participants were then obtained from infor- mation provided by the initial participants, via snowball sampling (Struwig \& Stead, 2001). This technique was used to locate possible participants for the study.

Participant selection procedure

The Down Syndrome Association of South Africa supplied a list of 16 parents with children with Down syndrome aged between two and five years from their membership list. The head of CHRIB granted permission to use the CHRIB database to identify possible participants in the study and a list of nine families were obtained. All the potential participants were contacted by telephone requesting their participation in the research study. Of the 25 parents from the combined list received from the Down Syndrome Association of South Africa and CHRIB database, 15 verbally agreed to participate. Through snowball sampling, another nine parents were contacted and all of these verbally agreed to participate. Participant information brochures and letters of informed consent were sent out to 24 parents with children with Down syndrome.

A total of 15 parents sent their letters of consent back and those parents were selected as participants for the re search study. All 15 questionnaires were returned after one reminder. The participant characteristics are described in Table 1.

According to Table 1, the characteristics of the participants provide the following profile of parents and their children with Down syndrome: The majority of the parents were in their middle adult years, with the majority of their children with Down syndrome being the second or third born child. This may indicate that the participants were, experienced in parenting. While the majority of the families spoke English as their first language, most of the families were bilingual. There were also a variety of different languages spoken at home, reflecting the multilingual nature of South African families (Swanepoel, 2004). The participants were geographically widespread, thus the means of communica- 
Table 2. Content of the questionnaire

SECTION 1: BIOGRAPHICAL INFORMATION

\begin{tabular}{|l|}
\hline \multicolumn{1}{|c|}{ Content } \\
\hline Information was gathered about the parents' \\
age, occupation and level of education, their \\
town of residence, languages spoken, number \\
of children, position of the child with Down \\
syndrome in the family, and the child's age.
\end{tabular}

SECTION 2: THE VALUE OF EMERGENT LITERACY

Questions included asking where parents heard about the importance of emergent literacy, whether they participated in developing their child's emergent literacy and where they received their information regarding the importance of emergent literacy.
This section was important as it provides background information regarding the participants and their children with Down syndrome. This provided the researcher with deeper understanding of the family (Shipley \& McAfee, 2004) and the data were used to interpret the results.
SECTION 3: THE MATERIALS PARENTS USE TO FACILITATE EMERGENT READING SKILLS
Questions were asked about the types of syndrome, where they obtained these books, their criteria for selecting books to read and additional literacy experiences to which the child was exposed. books parents read to their children with Down

This section provided information pertaining to the South African context. It was important to determine the value parents placed on emergent literacy so that speech-language therapists might know which guidelines should be provided to families with children with Down syndrome. Emergent literacy facilitates communication development and academic learning skills in children with Down syndrome (Kumin, 2003).

It was important to identify what materials parents were using to facilitate emergent literacy development. Reading material needs to be age appropriate in terms of how the book needs to be handled (e.g. cardboard pages versus paper pages) and what kind of information it provides (e.g. size of print and types of pictures). Literacy goes far beyond book-reading and is thus important to determine whether parents expose their children to the entire spectrum of emergent literacy experiences (Boudreau, 2005).

\section{SECTION 4: STRATEGIES AND METHODS PARENTS USE TO FACILITATE LITERACY} DEVELOPMENT

Questions were asked to determine the environment in which the child was read to and the strategies parents used while reading to their child.

\section{SECTION 5: FACTORS REGARDING TIME}

Aspects such as the amount of time spent reading and the time of day that reading occurs, were addressed.

\section{SECTION 6: PARENTAL NEEDS}

Questions regarding the specific needs parents had regarding emergent literacy. Additional space was provided for parents to supply their specific needs.
Research has shown that certain strategies and methods, such as joint book-reading, used in emergent literacy contribute to the development of language skills (Justice, 2006). It is important to describe how parents enhance book-reading in order to provide appropriate guidelines.

More time spent on emergent literacy development can result in more benefits for communication development (Kaderavek \& Sulzby, 1998). Identifying how much time parents spend on literacy activities may provide information where guidelines can again be given, since children with Down syndrome learn best if meaningful activities are repeated often (Kumin, 2003).

The identification of parental needs is an important emergent intervention principle (Rossetti, 2001), If parental needs are known, emergent intervention may be applied in assisting parents to focus on the emergent literacy development of their children with Down syndrome. tion via email and facsimile were advantageous. All the participants were well educated having completed matric and about half of the parents had tertiary qualifications. Most of the parents were employed. The majority of the children with Down syndrome had siblings and thus had opportunities for interaction with other children. Most of the children with Down syndrome had received speech-language therapy, which could imply that the participants were aware 
of the importance of early communication intervention.

Material

The materials used in the study were the participant information brochure, letter of informed consent and the selfadministered questionnaire. The questionnaire was made available in both English and Afrikaans and targeted the areas based on the main and sub-aims of the study. The questionnaire content and arguments to justify the inclusion of questions are summarized in Table 2.

Procedures

A pilot study was conducted to determine whether the material and procedures were appropriate and applicable for the study. A parent with similar participant characteristics as the target group was selected. The child with Down syndrome in the pilot study was aged 7 , slightly older than the children in the main study in order not to utilize a participant from the limited pool of participants available for the main study. The pilot study gave a clear indication that the questionnaire and information brochure would be suitable for the purposes of the study.

Validity and reliability

To ensure validity of the data collection instrument, the questions in the questionnaire were based on a review of recent literature regarding emergent literacy development of children with Down syndrome (Bird \& Buckley, 2007; Bochner et al., 2001; Boudreau, 2005). The pilot study increased the reliability of the questionnaire. The questionnaire was designed to ensure accurate and consistent data. Reliability amongst participants was further enhanced, as they all received the same questionnaire without prior knowledge about the questionnaire from the researcher.

Data Collection

The questionnaires were sent via email and/or facsimile, according to the participant's preference. Questionnaires sent via email or mail may pose certain problems. There are often low response rates, at times the questionnaires may be completed by someone other than the intended participant and participants may not understand some of the questions or how to complete the questionnaire (Struwig \& Stead, 2001). To ameliorate the disadvantages, the researcher enclosed an information brochure explaining the value of the research. The questions were easy to answer, well formulated and did not test knowledge. Participants were encouraged to share their views and may have felt positive about the opportunity to report on their practices to develop their children's literacy skills. Follow-up phone calls were made to remind participants of the deadlines for returning the questionnaires, but care was taken not to pressurize participants to reach a point of involuntary participation.

\section{Data Analysis}

The raw data were converted into more meaningful and interpretable information by means of encoding. The encod- ed information was entered on a spreadsheet (Microsoft Excel(C). Once the coding was done, the data were statistically analyzed and frequency counts, averages and ranges were determined. No inferential statistical analysis procedures could be carried out since the number of participants was limited (Leedy \& Ormrod, 2005). Text data were analysed according to recurring themes and reported as comments.

\section{Results and Discussion}

Sub-aim 1: The value parents attach to the development of emergent literacy development in their young children with Down syndrome

All 15 participants valued emergent literacy development. A total of $87 \%$ of participants regarded this developmental area as very important, while the remaining $13 \%$ viewed emergent literacy as moderately important. A study by Prinsloo (1998) showed that $80 \%$ of the parents valued the practice of book-reading with their young children with Down syndrome. The higher result obtained in the present study may be attributed to the time that has passed between the two studies and the improved resources and technology now available to parents. The high value placed by parents on emergent literacy development may also be a function of the nature of the study, i.e. parents could have concluded that a positive answer was desired.

A few participants also explained why they placed such a high value on the emergent literacy development of their children. Reasons included the fact that they knew the implications of emergent literacy on their child's future development. It therefore appears that participants knew that emergent literacy is the basis for further learning at school and independent functioning later on in life.

The different sources from which the participants received information about emergent literacy development are reported in Table 3.

Table 3. The different sources from which the participants received information about emergent literacy development $(N=15)$

\begin{tabular}{|ll|l|}
\hline \multicolumn{2}{|c|}{ Sources of information } & $\begin{array}{c}\text { Number of } \\
\text { participants }\end{array}$ \\
\hline 1. & Speech-language therapist & $\mathbf{9}$ \\
\hline 2. & $\begin{array}{l}\text { Popular media: Parent } \\
\text { magazines, television, internet }\end{array}$ & $\mathbf{6}$ \\
\hline 3. & $\begin{array}{l}\text { Physiotherapist, occupational } \\
\text { therapist, specialist in literacy, } \\
\text { child's teacher }\end{array}$ & $\mathbf{4}$ \\
\hline 4. & No information obtained & $\mathbf{3}$ \\
\hline 5. & $\begin{array}{l}\text { Own knowledge from field of } \\
\text { study (teacher) }\end{array}$ & $\mathbf{2}$ \\
\hline 6. & Friends & $\mathbf{2}$ \\
\hline 7. & Down Syndrome Association & $\mathbf{2}$ \\
\hline
\end{tabular}

Participants received emergent literacy information mostly from a speech-language therapist and also from other early intervention team members. This was a positive result and suggested that speech-language therapists and other professionals were keeping up with the new trends in emergent literacy development for young children with Down syndrome. Popular mass media also played an important role in providing information about emergent literacy.

Even though most of the participants were recruited from the Down Syndrome Association of South Africa, only two participants indicated receiving information on emergent literacy development from the Association. The Association is actively involved in promoting emergent literacy in publications such as the Down Syndrome Bulletin 
$(2000,2001,2002,2003$ and 2006) but the information may not have been noted by the parents in this study. It is a concern that three participants did not receive any information on emergent literacy. It therefore appears that much can still be done to ensure that all parents who have young children with Down syndrome receive information on emergent literacy.

The next question enquired about the people who read books to the child. It appeared that persons who read to the child with Down syndrome were mostly family members, i.e. mothers (14), the fathers (10), grandmothers (9) and siblings. Only one child in the study was not read to by anyone. Even though being read to is only one activity of all the possible emergent literacy experiences, it is considered as the most important. Shared book-reading promote timely development of oral language and other areas of emergent literacy development (Ezell \& Justice, 2005). According to Ezell (2006) storybooks offer an opportunity to decontextualise language, which implies that the events and concepts are not restricted to the here and now. Decontextualised language may be more linguistically advanced than contextualised language and therefore challenges cognitive development. Children with Down syndrome may therefore require support in understanding the decontextualised discourse of storybooks. Knowing that most of the children with Down syndrome in the present study were exposed to joint book-reading through their parents and others implies that their communication development and their future academic success could be enhanced by these experiences.

It appeared that grandparents and siblings played a significant role in emergent literacy experiences and it is recommended that the speech-language therapist should utilize them as an additional source to facilitate the development of the emergent literacy skills of children with Down syndrome. Since children with Down syndrome learn more effectively if skills are reinforced, the option of multiple readers in joint book-reading should be utilised (Spiker \& Hopmann, 1997).

Sub-aim 2: The materials participants report using to facilitate the development of emergent literacy in their young children with Down syndrome

Most participants used children's and baby books when reading to their children. Depending on the child's developmental age, these types of books are appropriate for the preschool years, which was the age range of the children in this study. The extensive use of children's books instead of baby books may not have been appropriate for all the children in the study, who may be on a lower developmental level. According to Kumin (2003) books with cardboard pages, flaps, and touch-and-feel features help children to explore and manipulate books, thus making the reading experience more enriching. Cardboard books are more durable and are thus a good alternative for the child who mishandles books. As a result of low muscle tone, cardboard books make book handling and turning the pages an easier task for the child with Down syndrome (Ezell \& Justice, 2005; Kumin, 2003).

Ten participants indicated using magazines as material to read to their children. Magazines are not the optimal reading source for young children because the size and type of paper is unsuitable for young children in the oral phase of mouthing objects (Kritzinger \& Louw, 1997). Homemade books, photo albums, birthday cards given to the child, toys with letters and words, flash cards and multimedia apparatus were used to a limited extent by the participants. The results therefore indicated that the participants require information about appropriate emergent literacy materials for their children.

Most participants reported that they bought their own books for their children or they have their own collection of books. This was a positive result as it showed that participants did not have resource needs to obtain books. Most participants reported that they had more than nine books available for their children.

Participants also indicated the content of books they had for their children to read. The books ranged from books about different concepts such as colours and shapes, books with vocabulary on certain topics, such as the body and animals, general vocabulary, such as a child's first 100 words, books with narratives such as Disney stories, picture books and books with nursery rhymes. Books with different physical characteristics such as pages with tactile and auditory stimulation were also listed as being used by the participants. This large variety of books indicated that children were exposed to many different book-reading experiences and these experiences were likely to enhance the child's development. There are currently a large variety of books for young children available in stores (Owens, 2006) and it appears that the participants in this study were making use of these resources. The participants' educational level and parenting experience (see Table 1) may have contributed to the knowledge they possessed regarding the selection of different books available for young children.

Table 4 indicates the criteria participants reported using when selecting reading material for their child. The illustrations in the book, the child's level of interest and the story line were the three most important criteria for participants when choosing a book. The illustration in a book is central to sustaining the child's attention and enhancing understanding (Ezell \& Justice, 2005). It appears that the participants selected books according to the most important criterion to maintain their child's interest. Participants also reported choosing books with bold graphics and few words, which according to Kumin (2003) are appropriate for children at the emergent literacy level. Although participants may have needed guidance on the variety of sources and appropriate materials they could use for emergent literacy development in their children, they appeared to know how to choose appropriate books.

Table 5 indicates the different literacy experiences to which participants exposed their children, apart from that of book-reading. In general, it appears that the majority of participants did not expose their children to a wide variety of experiences. This may have been due to a lack of knowledge and a lack of information provided by speech-language therapists and other information sources regarding the variety of emergent literacy experiences. A few participants added comments on the questionnaire and wrote that they thought exposure to some of these literacy experiences was too advanced for their child with Down syndrome. Exposure to experiences such as being made aware of brand 
Table 4. Criteria participants use to select reading material $(N=15)$

\begin{tabular}{|l|l|}
\hline \multicolumn{1}{|c|}{ Criteria } & Value \\
\hline $\begin{array}{l}\text { According to the pictures and/or } \\
\text { illustrations in the book }\end{array}$ & 13 \\
\hline According to child's level of interest & 12 \\
\hline - According to the story line & 10 \\
\hline $\begin{array}{l}\text { According to bold graphics (e.g. few } \\
\text { yet bold words per page) }\end{array}$ & 7 \\
\hline - According to child's attention span & 5 \\
\hline - According to the length of the story & 4 \\
\hline $\begin{array}{l}\text { According to the familiarity of the } \\
\text { story }\end{array}$ & 3 \\
\hline $\begin{array}{l}\text { According to child's familiarity of the } \\
\text { story }\end{array}$ & 2 \\
\hline $\begin{array}{l}\text { Do not have criteria but rather give } \\
\text { any book for child to read }\end{array}$ & 1 \\
\hline
\end{tabular}

names and logos does not happen formally but rather within the environmental context where print recognition may occur (Owens, 2006) and it is the task of the speech-language therapist to make parents aware of the variety of incidental emergent literacy experiences to which they can expose their children.

Sub-aim 3: Participants' reports on how they facilitated the emergent literacy of their children

Almost all the participants read to their children in a comfortable environment in their homes. Many participants ensured that the environment was well lit and sat next to their child while reading, or the child sat on the parent's lap. It appeared that participants were aware of the benefit of books being shared by both parent and child when positioned in this way (Ezell \& Justice, 2005). Only a few participants reported that they limited background noise while reading. Limiting background noise is an important strategy to enhance joint book-reading to children with Down syndrome, as they are at risk for poor listening skills (Hugo, Louw, Kritzinger \& Smit, 2000) due to recurrent otitis media and auditory processing difficulties (Kumin, 2003).

Many participants indicated that they took the lead to read to their children as well as participatd in interactive book-reading where they elicited participation from their children. Some parents indicated that they combined three approaches i.e. reading to their child without eliciting much interaction, participating in joint book-reading and leaving their child to read alone. According to Ezell and Justice (2005) joint book-reading is the ideal reading activity as both parents and children are active participants. It appears that parents may need more information regarding joint book-reading and its benefits.

Most participants regarded reading as play time. This .was a positive result as children learn best through their play experiences and when the experiences are active, pleasurable, spontaneous and voluntary in their involvement with the environment (Owens, 2006). Early reading experience should be fun since the advantage is to create a positive attitude towards reading in the future (Justice, 2006). Literacyenriched play settings foster children's exposure to print and interactions with other literacy experiences (Kaderavek \&
Table 5. Literacy experiences participants expose their children to $(N=15)$

\begin{tabular}{|c|c|}
\hline Emergent literacy experiences & Value \\
\hline - Encourage child to scribble & 12 \\
\hline - Draw child's attention to words on toys & 7 \\
\hline $\begin{array}{l}\text { Teach child to recognize their name and } \\
\text { siblings' names in print }\end{array}$ & 7 \\
\hline $\begin{array}{l}\text { Draw child's attention to words on food } \\
\text { items or to specific brand names }\end{array}$ & 5 \\
\hline $\begin{array}{l}\text { Draw child's attention to words or } \\
\text { numbers on clothing }\end{array}$ & 4 \\
\hline $\begin{array}{l}\text { Draw child's attention to letters/numbers } \\
\text { on your cell phone }\end{array}$ & 4 \\
\hline $\begin{array}{l}\text { Draw child's attention to posters or } \\
\text { pictures with print }\end{array}$ & 3 \\
\hline - Point out words on the television screen & 3 \\
\hline $\begin{array}{l}\text { Draw child's attention to billboards while } \\
\text { driving }\end{array}$ & 2 \\
\hline $\begin{array}{l}\text { Draw child's attention to road signs while } \\
\text { walking and/or driving }\end{array}$ & 1 \\
\hline $\begin{array}{l}\text { - Point out car's registration number and/or } \\
\text { logo }\end{array}$ & 1 \\
\hline - Point out street name and house number & $\mathbf{0}$ \\
\hline $\begin{array}{l}\text { Draw child's attention to words on } \\
\text { computer screens and letters on } \\
\text { keyboards }\end{array}$ & $\mathbf{0}$ \\
\hline
\end{tabular}

Justice, 2004).

Table 6 indicates the various strategies parents reported using during reading activities. It appeared that parents had an idea about certain strategies but were not fully aware of all the strategies that are available to use with their children during reading activities. These strategies, compiled as a checklist in the questionnaire, can be viewed as intervention techniques to train parents to use while reading to their children (Justice, 2006).

Sub-aim 4: Participant perceptions of the time they spent on facilitating the emergent literacy development of their young children

Most of the participants' children were read to once a day, for 10-15 minutes, four to six days per week. A few participants indicated they read for less than 10 minutes because of their child's short attention span. According, to Ezell and Justice (2005) children should be read to on a daily basis with a recommended length of a 10-minute session. Each child is, however, different and these guidelines should be adjusted to suit each family. Most participants reported that they read for an appropriate amount of time and some for even longer. The appropriate and extended time parents read to their children may be attributed to the criteria parents used when selecting books, as seen in Table 4, as well as the strategies parents reported using, in Table 6, which could help to sustain their child's attention. Justice (2006) suggests that reading on a regular basis is more important than the length of a reading session. Most participants appeared to be reading on a regular basis to their children, but about half of the participants indicated that they did not have a specific reading routine. Having a regular reading routine may assist children to anticipate reading time and help to teach children about routine in other daily activities. 
Table 6. The strategies participants used while reading to their children with Down syndrome $(N=15)$

\begin{tabular}{|c|c|}
\hline Strategies & Value \\
\hline - Use an animated voice & 11 \\
\hline - Use short sentences & 10 \\
\hline - Read favorite books very often & 10 \\
\hline Make reading fun and enjoyable & 10 \\
\hline $\begin{array}{l}\text { Adapt the story to child's level of } \\
\text { understanding }\end{array}$ & 10 \\
\hline - Read at a rate child can cope with & 9 \\
\hline $\begin{array}{l}\text { Repeat and practice words that are } \\
\text { becoming more familiar with book- } \\
\text { reading }\end{array}$ & 8 \\
\hline Expand on the stories that are read & 8 \\
\hline $\begin{array}{l}\text { Link the pictures in the book to real } \\
\text { world experiences }\end{array}$ & 8 \\
\hline $\begin{array}{l}\text { Show real objects related to the } \\
\text { pictures in the story }\end{array}$ & 7 \\
\hline - Use a variety of reading materials & 7 \\
\hline - Let child talk and tell the story & 6 \\
\hline $\begin{array}{l}\text { - Only read selected words from the } \\
\text { story }\end{array}$ & 4 \\
\hline - Read the story word for word & 4 \\
\hline - Use pauses while reading to child & 4 \\
\hline Ask open-ended questions & 3 \\
\hline Take turns while reading & 3 \\
\hline - Sound out the letters in words read & 1. \\
\hline $\begin{array}{l}\text { - Incorporate reading into activities of } \\
\text { daily life }\end{array}$ & 1 \\
\hline - Adapt the books for easy handling & $\mathbf{0}$ \\
\hline
\end{tabular}

Even though not all participants had a specific reading routine, most of them read to their children in the evenings during the week and on weekends. This may be attributed to the fact that most parents in the study were employed (see Table 1) and therefore only had time to read to their children in the evenings during the week and on weekends.

Sub-aim 5: The needs of participants regarding teaching emergent literacy to their young children with Down syndrome

The participants experienced a number of problems when trying to read to their children. Many parents felt that they did not have time to read to their children because they were too busy. Participants commented that apart from the time constraints they experienced, there were many other developmental issues of their children with Down syndrome that needed to be considered. Emergent literacy was not always the priority. Many participants also mentioned that their child's attention span was too short for them to appreciate reading.

Some parents also indicated that they were too tired when they get home from work to still read to their children. One solution would be to ask significant others to read to the child if parents' schedules are too hectic and if they are too tired to read to their children (Ezell \&Justice, 2005). It is important for the speech-language therapist to ensure that parents and significant others receive training and information about establishing a reading routine and allocate sufficient time for the activity.
The participants also utilized the opportunity to describe their needs in terms of the emergent literacy development of their children. Many parents identified their need to know what reading material was age appropriate. Table 4 showed that parents have knowledge when selecting books for their children to read, but age appropriate selection requires specific knowledge of a child's literacy developmental functioning. The speech-language therapist can assess the child's literacy skills, as they have specialized knowledge regarding development and emergent literacy. Participants therefore needed guidelines in terms of choosing books according to their child's developmental age.

Many participants identified the need to learn effective reading strategies and how to teach reading to their children with Down syndrome. Table 6 provided an indication that parents were aware of some strategies to teach reading but all reported a need to learn more, especially to keep their child's attention. Teaching reading to children with Down syndrome: a guide for parents and teachers by Logan Oelwein (1995) and Early communication skills for children with Down syndrome. A guide for parents and professionals by Kumin (2003) are two resources that provide specific strategies for the facilitation of emergent literacy skills for children with Down syndrome.

One participant indicated that it was only after having her child's eyesight tested and ascertaining that her child was diagnosed as extremely far-sighted, that her child's ability to participate in early reading experiences improved. After her child received glasses, the participant reported that her child's concentration and interest in reading had "grown in leaps and bounds". Since children with Down syndrome are at risk for visual problems (Kumin, 2003) their eyes should be tested in order to ensure optimal literacy experiences and book-reading.

Lastly, participants described what they liked and enjoyed most about reading with their children. The majority of the participants described the joy they experienced in the closeness, interaction and time spent together during their reading activities with their children. Seeing their children's reactions and facial expressions when understanding and recognizing familiar pictures and stories was another aspect parents enjoy while reading to their children. Participants also derived pleasure from the excitement their children showed during reading activities. According to Owens (2005) reading is a highly social activity in which both parents and children participate. Sensitive, responsive and supportive strategies used by parents during book-reading is said to support positive parent-child interaction (Roberts et al., 2005).

It was clear that participants were actively promoting and enjoyed the emergent literacy development of their children, but they had certain needs that should be addressed by the speech-language therapist working in early communication intervention.

\section{Conclusions and Recommendations}

The main aim of the study was achieved by describing the participants' perceptions and practices of various aspects of emergent literacy development in their young children with Down syndrome. The questionnaire proved to be applicable to collect sufficient data to describe the results of a 
literate group of participants and to provide guidelines for intervention.

The results indicated that participants valued emergent literacy development and most thought that it was very important for their children. It appeared that participants had a general knowledge of book-reading but they were unaware of the broader spectrum of emergent literacy experiences such as the exposure to logos and posters or pictures with print. The majority of participants were unaware of daily life experiences that may provide rich opportunities for enhancing emergent literacy development in their children. Participants also needed guidelines on how to facilitate the broader spectrum of emergent literacy experiences such as exposure to print on clothing or cereal boxes so that their children could learn from these diverse experiences and gain a stronger foundation for their future literacy development. Since computers play such an important role in accessing information in the $21^{\text {st }}$ century, the facilitation of basic computer skills in preschool children may be considered as an expansion on emergent literacy development.

While most of the participants received information regarding emergent literacy from their speech-language therapists, it appeared that there were speech-language therapists who did not provide information to their clients regarding this important developmental area. The effect of the emergent attainment of literacy skills on a child's later achievements emphasizes the importance of developing an effective model of emergent literacy intervention (Kaderavek \& Justice, 2004). According to Kaderavek and Justice (2004) the embedded-explicit model of emergent literacy intervention takes into account natural, meaningful and intentional daily experiences of literacy as well as focused clinician directed intervention to target skills necessary for later reading success. It is important for the speech-language therapist to use a model of emergent literacy intervention to design emergent literacy programmes, particularly for populations of children at risk for communication disorders, such as children with Down syndrome (Kaderavek \& Justice, 2004).

The results revealed that participants were aware of the various types of reading materials available for their children with Down syndrome but they were unaware of the developmental appropriateness of the books for their children. Participants also revealed knowledge with regard to the most important criteria that might be used when selecting books for their children. Participants reported that they selected books according to illustrations, the child's level of interest and the story line, but more criteria may be used to select developmentally appropriate books for children. It is the role of the speech-language therapist to assess the developmental age of children and provide guidelines to participants regarding relevant types of books, i.e. books with cardboard pages or children's books that would be best suited for the child's developmental age. The results indicated that specific information needs to be provided by the speechlanguage therapist regarding how to choose books, which books are developmentally appropriate and the criteria that one needs to adhere to when selecting books, such as the size of pictures.

The results also showed that most participants ensured that the reading environment was conducive to learning.
While some of the participants acknowledged participating in joint book-reading, it would benefit parents to be informed of the advantages of joint book-reading with their children with Down syndrome instead of leaving children to page through books on their own. Joint book-reading requires care and attention to important elements such as the physical arrangement of seating, materials selected, reading style and the opportunity to engage in conversation with the child which may yield impressive results over time with regard to children's language and emergent literacy skills (Ezell \& Justice, 2005).

The results further indicated that participants needed training regarding the various strategies that can be used during emergent literacy experiences such as asking the child open-ended questions and using pauses while reading to the child. Again, the speech-language therapist has an important role to fulfill in providing information and training on these different strategies and a rationale as to why these strategies may benefit emergent literacy experiences. It is also important for the speech-language therapist to comment on and commend parents on their efforts with regard to the time they spend reading to their children with Down syndrome, in order to encourage regular joint book-reading routines.

It appeared that the greatest concerns expressed by participants were that they did not always have time to read to their children, their child's attention span was too short and that they as parents were often too tired to engage in reading activities. The speech-language therapist can assist in providing parents with realistic guidelines in terms of what can be done to alleviate these pressures. As suggested by Ezell and Justice (2005), a reading schedule can be created to suit each family, which can include significant others to help during specific reading times. Another solution would be to incorporate emergent literacy activities within the daily activities of the child and family (Kumin, 2003). The speech-language therapist has a role to play in facilitating ideas that can be used in order to meet individual family needs, so that a family-centered approach to emergent literacy intervention may be followed.

The clinical implications of this study are that speechlanguage therapists need to provide the appropriate and comprehensive guidelines to parents with children with Down syndrome with regard to emergent literacy develop ment as part of a comprehensive emergent intervention pro $\top$ gramme. Speech-language therapists need to keep abreast of new research and should inform and train parents regarding techniques to enhance the development of emergent literacy skills in their children with Down syndrome.

Further implications are that parents need to be recognized and guided in what they are already doing for their children's literacy development in order to follow an assetbased approach. More emphasis needs to be placed on utilizing the broader spectrum of emergent literacy experiences as optimal learning opportunities. In order to ensure full participation in literacy experiences the vision of children with Down syndrome should be tested at a young age. Visual problems as well as hearing difficulties in children with Down syndrome may interfere with emergent literacy development and should be diagnosed and treated. 
In order to summarize $\mathrm{pa}^{-}$ rental needs that emerged from the results, a comprehensive framework for emergent literacy intervention in young children with Down syndrome is presented in Figure 1 . The different guidelines may be used by speechlanguage therapists to select goals for emergent literacy intervention, and to expand the current focus of emergent literacy facilitation of both therapists and parents.

A number of limitations were identified throughout the study. Although a country-wide survey was possible, only a small group of parents with children with Down syndrome agreed to participate in the study. Most of the participants came from similar cultural backgrounds, representing middle class families. An attempt was made through the Down Syndrome Association of South Africa to include a culturally diverse participant sample but this was not achieved. Thus the results of this study cannot be generalized to all cultural groups within the South African context.

There are a number of recommendations for further research. It is recommended that this study be replicated with a larger target population that includes different cultural groups. Separate studies should also be conducted with participants with low literacy skills and illiterate parents. This would change the research design to a qualitative study where interviews would need to be carried out, but some of the questions in the questionnaire may still be relevant. It has been demonstrated by Armstrong (1998) that parents with low literacy skills may enhance their own literacy skills when they are trained to read books to their children.

Further recommendations are to adapt and apply this study to other at-risk populations such as young children with cleft-lip and palate in order to identify a broader spectrum of emergent literacy training needs so that speech-language therapists can provide specific guidelines for emergent literacy intervention to different populations of children with special needs. involvement literacy development intervention
1. Conduct a comprehensive assessment to determine the child's language and cognitive functioning

The assessment should include the use of a joint book-re

- The questionnaire designed for this study may also be used as a self-completed assessment instrument

2. Refer the child for a vision test in order to eliminate visual barriers to

3. Based on the assessment results, a comprehensive emergent literacy intervention program should be designed for the child, family and caregivers. The following topics should be included:

\begin{tabular}{|c|c|}
\hline & $\begin{array}{l}\text { Discussing background information on emergent literacy } \\
\text { development and long-term advantages for children with Down } \\
\text { syndrome }\end{array}$ \\
\hline & $\downarrow$ \\
\hline & $\begin{array}{l}\text { Providing knowledge of all the opportunities to enhance emergent } \\
\text { literacy development in everyday life experiences }\end{array}$ \\
\hline & $\downarrow$ \\
\hline . & $\begin{array}{l}\text { Using specific criteria to select relevant books to match the child's } \\
\text { language and cognitive skills }\end{array}$ \\
\hline & $\downarrow$ \\
\hline & $\begin{array}{l}\text { Using a set of criteria to select developmentally appropriate books } \\
\text { as the child grows }\end{array}$ \\
\hline & $\downarrow$ \\
\hline & $\begin{array}{l}\text { Creating a quiet environment and enjoyable atmosphere to } \\
\text { facilitate joint book-reading }\end{array}$ \\
\hline & $\downarrow$ \\
\hline & $\begin{array}{l}\text { Training parents to implement regular joint book-reading routines } \\
\text { with their children }\end{array}$ \\
\hline & 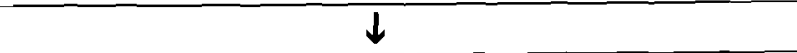 \\
\hline & $\begin{array}{l}\text { Guiding parents to utilize family members and caregivers to assist } \\
\text { in the child's joint book-reading routines, compensating for time } \\
\text { pressures and constraints }\end{array}$ \\
\hline & $\downarrow$ \\
\hline & $\begin{array}{l}\text { Train parents to use specific strategies during joint book-reading to } \\
\text { facilitate vocabulary enrichment and improved attention }\end{array}$ \\
\hline
\end{tabular}

Figure 1. A framework with guidelines for goal selection in emergent literacy intervention for young children with Down syndrome

Further research can be conducted to determine the value that speech-language therapists place on the emergent literacy development in young children with Down syndrome and to determine what they do in emergent intervention with regard to emergent literacy development. The current study indicated that not all speech-language therapists giving therapy to the participants' children provided information on emergent literacy development. As a component of early communication intervention, the importance of emergent literacy intervention in young children with Down syndrome should be recognized by speech-language therapists, as "emergent literacy experiences should be a regular, enjoyable part of life for the young child with Down syndrome. Reading is an important, empowering skill and helping the young child with Down syndrome to read is an effort that will have great rewards" (Kumin, 2003, p.291). 


\section{References}

Armstrong, M. B. (1998). Storybooks to literacy: A collaborative shared reading project. Infant-Toddler Intervention. The Transdisciplinary Journal, 8, 4, 365-375.

ASHA. (2001). Roles and responsibilities of speech-language pathologists with respect to reading and writing in children and adolescents (Technical Report), Rockville, MD: ASHA.

Bennett, K. K., Weigel D. J., \& Martin, S. S. (2002). Children's acquisition of early literacy skills: Examining family contributions. Early Cbildbood Research Quarterly, 17, 295-317.

Bird, G., \& Buckley, S. J. (2007). Reading and writing for infants with Down syndrome (0-5) years. Retrieved February 16, 2007 from Down Syndrome Information Network Website: http:// www.information.downsed.org/library/dsii/07/01.

Bochner, S., Outhred, L., \& Pieterse, M. (2001). A study of functional literacy skills in young adults with Down syndrome. International Journal of Disability, Development and Education, 48, 1, 67-90.

Boudreau, D. (2005). Use of a parent questionnaire in emergent and early literacy assessment of preschool children. Language, Speech and Hearing Services in Schools, 36, 33-47.

Boudreau, D. (2002). Literacy skills in children and adolescents with Down syndrome. Reading and Writing: An Interdisciplinary Journal, 15, 497-525.

Buckley, S. J. (2000). Speech and language development for individuals with Down syndrome. An overview. Retrieved February 16, 2007 from The Down Syndrome Educational Trust Website: http://www.downsyndrome.org.za/main.aspx?artid $=67$.

Down Syndrome Association Tshwane. Down Syndrome Bulletin. December 2006, 12, 2, 20-21; August 2003, 9, 2, 23-25; December, 2002, 8, 3, 38-42; September, 2001, 7, 2, 8-10; December, $2000,6,3,28-29$.

Elias, G., Hay, I., Homel. R., \& Freilberg, K. (2006). Enhancing parent-child book reading in a disadvantaged community. Australian Journal of Early Cbildhood, 31, 1, 20-26. March.

Ezell, H. K., \& Justice, L. M. (2005). Shared Storybook Reading. Building Young Children's Language and Emergent Literacy Skills. Baltimore: Paul H. Brookes Publishing Co. Inc.

Hugo, R., Louw, B., Kritzinger, A., \& Smit, G. J. (2000). Listening behaviour in children at risk for communication delay. InfantToddler Intervention. The Transdisciplinary Journal, 10, 1, 47-53.

Justice, L. M. (2006). Clinical Approaches to Emergent Literacy Intervention. San Diego: Plural Publishing Inc.

Kaderavek, J. N., \& Justice, L. M. (2004). Embedded-explicit emergent literacy intervention I: Background approach and description of approach. Language, Speech and Hearing Services in Schools, 35, 201-211. July.

Kaderavek, J. N., \& Sulzby, E. (1998). Parent-child book reading. An observational protocol for young children. American Journal of Speech Language Patbology, 7, 1, 33-43.

Kritzinger, A., \& Louw, B. (1997). A description of joint bookreading practices of mothers and their young children, $0-2$ years. Clinica: Applications in Clinical Practice of Communication Pathology. Monograph 2, 61-77. University of Pretoria.

Kritzinger, A., \& Louw, B. (2002). A comprehensive assessment protocol for infants and toddlers at risk for communication disorders. Part II. Clinica: Applications in Clinical Practice of Communication Pathology. Monograph 6, 3-17. University of Pretoria.
Kritzinger, A., Louw, B., \& Rossetti, L. M. (2001). A transdisciplinary conceptual framework for early identification of risks for communication disorders in young children. The South African Journal of Communication Disorders, 48, 33-44.

Kritzinger, A., \& Steenkamp, L. (2006). Communicaiton development of a young child with foetal retinoid syndrome: A sevenyear follow-up study. The South African Journal of Communication Disorders, 53, 39-48

Kumin, L. (2003). Early Communication Skills for Children with Down Syndrome. A Guide for Parents and Professionals. (2nd ed.). Bethesda: Woodbine House, Inc.

Leedy, P. D., \& Ormrod, J. E. (2005). Practical Research: Planning and Design. ( $8^{\text {th }}$ ed.). USA: Merril Publishing Company.

Logan Oelwein, P. (1995). Teaching Reading to Children with Down Syndrome: A Guide for Parents and Teachers. Bethesda, MD: Woodbine House.

Owens, R. E. (2005). Language Development. An Introduction. (6 $6^{\text {th }}$ ed.). USA: Allyn \& Bacon.

Owens, R. E. (2006). Child language disorders: A functional conversational approach to assessment and intervention. Seminar presented by the Department of Communication Pathology at the University of Pretoria, 19 August 2006.

Pieterse, N. (1998). A description of joint book-reading practices of caregivers and their young children in the Eersterust community. Unpublished BCommunication Pathology Dissertation, University of Pretoria.

Prinsloo, R. (1998). Ouers van kinders met Downsindroom: Persepsies en praktyk van vroeë geletterdheidsvaardighede. Unpublished BCommunication Pathology Dissertation, University of Pretoria.

Roberts, J., Jurgens, J., \& Burchinal, M. (2005). The role of home literacy practices in preschool children's language and emergent literacy skills. Journal of Speech, Language and Hearing Research, 48, 345-359.

Rossetti, L. M. (2001). Communication Intervention. Birth to Three. ( $2^{\text {nd }}$ Ed.). Australia: Singular Thomson Learning.

Shipley, K.G., \& McAfee, J.G. (2004). Assessment in Speech-Language Pathology. A Resource Manual. ( $3^{\text {rd }}$ ed.). USA, Delmar Learning.

Spiker, D., \& Hopmann, M.R. (1997). The effectiveness of early intervention for children with Down syndrome. In M.J. Guralnick. The Effectiveness of Early Intervention. Baltimore MD: Paul H. Brookes Publishing Co.

Struwig, F. W., \& Stead, G. B. (2001). Planning, Designing and Reporting Research. Cape Town: Pearson Education SA.

Swanepoel, D. (2004). A review of the South African context: Information for community-based speech-language and hearing services. Clinica: Applications in Clinical Practice in Communication Pathology. Monograph 7, 11-16. University of Pretoria.

Willenberg, I. (2007). Foundations for literacy: Emergent literacy competencies of Grade R learners on the Cape Flats. The South African Journal of Communication Disorders, 54, 20-28. 